comprises while, as Atroshi and colleagues have shown, an accurate diagnosis is associated with success after adequate decompression by any means.

Standardised diagnostic criteria are lacking for many, if not most, medical conditions. The term "gold standard" is often used to imply that there is a definitive diagnostic criterion for a given condition, but gold standards exist only by consensus. Despite the fundamental role played by diagnosis in determining treatment and prognosis, little attention has been paid to the effect variations in diagnostic criteria may have on treatment outcomes.

Indeed, much evidence on treatment outcomes is flawed because diagnostic criteria are rarely explicitly described in intervention studies. Inconsistencies in diagnostic practices for common medical conditions may lead to differing patterns of resource use, including the use of diagnostic tests and variations in estimates of disease prevalence, treatment, and outcomes.

Carpal tunnel syndrome is commonly diagnosed by a broad range of medical and surgical specialists as well as by primary care doctors working in a wide variety of practice settings. The best diagnostic criteria for the syndrome have not been established, and there is considerable disagreement as to the relative importance of various clinical findings. ${ }^{8}$ To a certain extent, the absence of consensus on the best diagnostic criteria for the syndrome is related to a general reliance on the results of electrodiagnostic testing as a diagnostic gold standard.

Unfortunately, the electrophysiological criteria for making a diagnosis of carpal tunnel syndrome may vary substantially between laboratories. In addition, like all laboratory tests, electrodiagnostic tests may yield both false positives and negatives. The results of electrodiagnostic tests are best interpreted in the context of clinical findings. Electrophysiological data alone cannot be taken as reliable evidence of the diagnosis of carpal tunnel syndrome, although they may be helpful in cases where there is uncertainty after a careful clinical evaluation. Under these circumstances the outcome of electrodiagnostic testing should be seen as raising or lowering the probability of the syndrome first established on clinical grounds.

The problems surrounding the evaluation and treatment of carpal tunnel syndrome, including the impact on outcomes such as workers' compensation, is a good example of the challenges facing clinical researchers in a variety of subjects. Until there is consensus on the diagnostic criteria for the disease in question, there will always be a risk of comparing apples with oranges.

For carpal tunnel syndrome, these diagnostic variations have been at least partially responsible for wide variations in the observed prevalence of the condition in different workplace settings. This has led to possibly erroneous conclusions regarding the aetiological role of certain types of work in the development of the condition, with enormous implications for insurers, patients, and employers. There are well established strategies for developing and measuring this type of consensus, such as the Delphi technique. ${ }^{9}$ While this approach to standardising diagnostic criteria for common medical conditions may prove to be arduous, the benefits are clear and potentially far reaching.

Brent Graham director University of Toronto/University Health Network Hand Program

(Brent.Graham@uhn.on.ca)

Toronto Western Hospital, 399 Bathurst Street, Toronto, Ontario M5T 2S8, Canada

Competing interests: None declared.

1 Atroshi I, Larsson G-U, Ornstein E, Hofer M, Johnsson R, Ranstam J. Outcomes of endoscopic surgery compared with open surgery for carpal Outcomes of endoscopic surgery compared with open surgery for carpal
tunnel syndrome among employed patients: randomised controlled trial. tunnel syndrome amon $2006 ; 332: 1473-6$.

2 Brown RA, Gelberman RH, Seiler JG 3rd, Abrahamsson SO, Weiland AJ, Urbaniak JR, et al. Carpal tunnel release. A prospective, randomized assessment of open and endoscopic methods. J Bone Joint Surg Am 1993;75:1265-75.

Macdermid JC, Richards RS, Roth JH, Ross DC, King GJ. Endoscopic versus open carpal tunnel release: a randomized trial.J Hand Surg [Am] 2003;28:475-80

4 Saw NL, Jones S, Shepstone L, Meyer M, Chapman PG, Logan AM. Early outcome and cost-effectiveness of endoscopic versus open carpal tunnel release: a randomized prospective trial. J Hand Surg [Br] 2003;28:444-9.

5 Hunt TR, Osterman AL. Complications of the treatment of carpal tunnel Hunt TR, Osterman AL. Complication
syndrome. Hand Clin 1994;10:63-71.

6 Kessler FB. Complications of the management of carpal tunnel syndrome. Hand Clin 1986;2:401-6.

7 Crombie DL, Cross KW, Fleming DM. The problem of diagnostic variability in general practice. J Epidemiol Community Health 1992;46:44754.

8 Graham B, Dvali L, Regehr G, Wright JG. Variations in diagnostic criteria for carpal tunnel syndrome among Ontario specialists. Am J Ind Med 2006;49:8-13.

9 Graham B, Regehr G, Wright JG. Delphi as a method to establish consensus for diagnostic criteria. J Clin Epidemiol 2003;56:1150-6.

\title{
Rational prescribing for children
}

\author{
In an evidence based desert, safe and appropriate treatment is difficult and too \\ easily exploited
}

$\mathrm{M}$ any drugs used to treat children are unlicensed or off label. ${ }^{1}$ Three recent news stories highlight how children, like adults, are at risk from overprescribing and inappropriate prescribing. A systematic review conducted by the National Institute for Health and Clinical Excellence has shown fluoxetine (with or without cognitive behavioural therapy) to be the only selective serotonin reuptake inhibitor that is more effective than placebo in teenage patients with depression. ${ }^{2}$ Furthermore, the US Food and Drug Administration and the Medicines Healthcare Products
Regulatory Agency have shown that most randomised controlled trials have reported higher rates of "possibly suicide-related event" and "suicide attempt event" among adolescents and children taking selective serotonin reuptake inhibitors than in those taking placebo. ${ }^{3}$ The systematic review on fluoxetine included children as young as 7 years old and found no conclusive evidence of increased suicidal behaviour or ideation in studies lasting seven to 12 weeks. ${ }^{2}$ It may be surprising or even confusing for the public, nevertheless, to find that the European Medicines Agency recently 
licensed fluoxetine for use in children as young as 8 years old (European Medicines Agency press release 6 June 2006). Furthermore, a new US study has just reported a marked increase in antipsychotic drug use in US children and adolescents with no robust evidence of any increase in psychotic illnesses. ${ }^{4}$ Indeed, the number of prescriptions for psychotropic drugs-including antipsychotics, antidepressants, and drugs for attentiondeficit/hyperactivity disorder-in children and adolescents has increased in most countries, catching up with trends in the United States. ${ }^{5}$

Societal influences no doubt affect such prescribing decisions. For example, the perceived need for treatment of attention-deficit/hyperactivity disorder is likely to increase in post-agrarian Western societies where passing exams becomes ever more important to gain a satisfactory job and pass rates in school exit exams continue to rise year on year.

Many drug trials (which are commonly industry sponsored) do not ask the right questions about new drugs, let alone test them on children. The trials usually test news drugs against placebo when they should test against established treatments. Furthermore, when an established treatment is already known to have an unacceptable side effect profile, further molecules derived from the primary entity will probably suffer the same fate. ${ }^{6}$

Thus it is worrying that, in an area with a very poor track record (slimming therapies), a new definition of child obesity and overweight has been agreed (apparently with industry influence) that would define far more children as obese. ${ }^{7}$ So far, only increased exercise, spending less time sitting in front of television or computer screens, and decreased consumption of carbonated drinks have been shown to be effective in reducing obesity in children. According to the proposed new definition, $25 \%$ of US toddlers and almost $40 \%$ of children aged 6-11 years could be classified as "overweight and obese." If the new definition is accepted and drugs for reducing obesity prove acceptable, these children will represent a very big market.

Well recorded catastrophes associated with drugs for children have led to new legislation that provides financial incentives to extend the testing of drugs to child patients. ${ }^{8}$ Led by the US Food and Drug Administration, ${ }^{9}$ the European Medicines Agency has followed suit. ${ }^{10}$ The agency now offers a licence extension to those who have conducted testing in children for new drugs and a newly created licence entitled "paediatric use marketing authorisation" (PUMA) for old drugs.

What challenges must be met and mechanisms used to ensure that good clinical studies can be practically achieved? The Medicines for Children Research Network has now been established in England by the Department of Health at a cost of $£ 20 \mathrm{~m}$. The network comprises six local research networks, coordinated from Liverpool, and will have the potential to recruit children from a child population of five million. The network's aim is to carry out high quality clinical studies and expand the evidence base in relation to drugs for children, both for new chemical entities and for those already used off label or unlicensed. For example, a randomised placebo controlled trial of melatonin in sleep disordered children will soon be conducted via the network, and funded by the Health Technology Assessment Programme of the Department of Health. Simultane- ously, the European Medicines Agency is coordinating the collaboration of many national European networks for research on drugs for children.

New non-invasive methods such as breath tests, saliva samples, reverse iontophoresis, and sparse data analysis for pharmacokinetic and pharmacodynamic testing of drugs will be more acceptable and less distressing to both children and parents, making data collection easier. ${ }^{11}$ However, such techniques still require further development, particularly in data analysis and interpretation.

Doctors prescribing drugs for children are already being helped by the British national formulary for children. ${ }^{12}$ This widely welcomed manual brings together available evidence concerning both licensed and unlicensed drugs for children, and a second edition will be published soon.

While these initiatives represent constructive steps forward, should we be prescribing psychotropic drugs or antiobesity drugs to young children when there are so few drops of rain in this evidence based desert? The answer must be the same as for adults: practitioners should only prescribe drugs with clear evidence of favourable ratio of benefit to risk. Practitioners need to remain wary of both industry influence and societal pressures.

\section{Alastair G Sutcliffe senior lecturer in paediatrics}

(icsi@rfc.ucl.ac.uk)

Royal Free and University College Hospital Medical School, University College London, London NW3 2PF

Ian Chi Kei Wong professor of paediatric medicines research

School of Pharmacy and Institute of Child Health University of London, London WC1N 1AX

Competing interests: ICKW is funded by a Department of Health Public Health Career Scientist Award to investigate the effects of psychotropic drugs in children. AGS is a principal contributor for the BNF for Children. AGS and ICKW are the assistant directors of the London Local Research Network of the Medicines for Children Research Network. The BMJ Publishing Group co-publishes the BNF for Children.

1 Conroy S, Choonara I, Impicciatore P, Mohn A, Arnell H, Rane A, et al for the European Network for Drug Investigation in Children. Survey of unlicensed and off label drug use in paediatric wards in European countries. $B M J$ 2000;320:79-82

2 National Institute for Health and Clinical Excellence. Depression in children: identification and management of depression in children and dren. idncintion an young people in primary care and specialist services. Second draft for consultation. www.nice.org.uk/pdf/Depn_child_2ndcons_\%20App_P.pdf (accessed 19 Jun 2006)

3 Wong ICK, Besag FMC, Santosh P, Murray ML. Use of selective serotonin reuptake inhibitors in children and adolescents. Drug Safety 2004;27:9911000 .

4 Olfson M, Blanco C, Liu L, Moreno C, Laje G. National trends in the outpatient treatment of children and adolescents with antipsychotic drug. Arch Gen Psychiatry 2006;63:679-85.

5 Wong ICK, Murray ML, Novak-Camilleri D, Stephens P. Increased prescribing trends of paediatric psychotropic medications. Arch Dis Child 2004;89:1131-2.

6 Yanovski SZ. Pharmacotherapy for obesity-promise and uncertainty. $N$ Engl J Med 2005;353:2187-9.

7 Moynihan R. Expanding definitions of obesity may harm children. BMJ Moynihan R. Exp Sutcliffe AG. Testing new pharmaceutical products in children. BMJ 2003;326:64-5

9 US Food and Drug Administration. The Pediatric Research Equity Act. Public Law 108-155 December 3, 2003. www.fda.gov/cder/pediatric/S650-PREA.pdf (accessed 19 Jun 2006).

10 Watson R. EU offers incentives to firms to produce medicines for children. BMJ 2006;332:1352

11 Royal College of Paediatrics \& Child Health. Safer and better medicines for children-developing the clinical and research base of paediatric pharmacology in the United Kingdom. London: RCPCH Publications, 2004.

12 British Medical Association, Royal Pharmaceutical Society of Great Britain, Royal College of Paediatrics \& Child Health, Neonatal and Paediatric Pharmacists Group. BNF for children. London: Pharmaceutical Press, 2005. 